\title{
Flutuação e gramaticalização no paradigma dos juntores em português: forma, significado e história de (na) bora que
}

Sanderléia Roberta Longhin-Thomazi*

\begin{abstract}
RESUMO: Neste trabalho, focalizo um tipo de mudança gramatical que consiste na criação de juntores perifrásticos a partir de fontes nominais usadas em contextos de oração relativa. Trata-se de um mecanismo de produção de perífrases que vem ampliando o instável paradigma dos juntores e ajudando a delinear a gramática do português. Uma construção resultante desse mecanismo é (na) hora que, sobre a qual proponho investigar forma, significado e história. A questão central é mostrar que a emergência de (na) hora que é uma instância de gramaticalização em curso, em que é possível flagrar etapas do processo gradual de sua constituição, tanto no que se refere à reorganização sintagmática dos itens, com consequente perdas morfológicas, como também no que se refere à constituição dos sentidos, com o surgimento de polissemias, que apontam para uma direcionalidade fundada no aumento de complexidade cognitiva.
\end{abstract}

Palavras-chave: junção; gramaticalização; polissemia.

\begin{abstract}
In this paper, I focus on one type of grammatical change consisting of creating periphrastic junctures from nominal sources used in relative clause contexts. This is a periphrase production mechanism that has been increasing the unstable paradigm of junctures and helping delineate Portuguese language grammar. One construction resulting from this mechanism is (na) hora que, in relation to which I propose to investigate form, meaning and history. The central aim is to show the emergence of (na) hora que, a grammaticalization instance in course, in which it is possible to catch stages of the its gradual constitution process, concerning both the syntagmatic reorganization of items with consequent morphological losses, and the constitution of meanings, with the origin of polysemies, pointing to a directionality grounded on the increase of the cognitive complexity.
\end{abstract}

Keywords: juncture; grammaticalization; polysemy

UNESP, Instituto de Biociências, Letras e Ciências Exatas, Departamento de Estudos Linguísticos e Literários, São José do Rio Preto/SP, 15.054-000. E-mail: thomazi@ibilce.unesp.br 


\section{Apresentação}

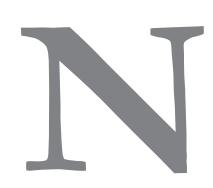

este artigo, analiso forma, significado e história de uma construção gramatical, que tem uso bastante generalizado no português paulista, especialmente em tradições textuais da oralidade, e cuja inserção no sistema traz consequências para o paradigma conjuncional do português. Refiro-me à construção perifrástica (na) bora que, que está perdendo a composicionalidade, i.é., a percepção de que se trata de um nome em contexto de sintagma preposicional modificado por uma oração relativa, e sendo reanalisada como um juntor que mobiliza um esquema hipotático no qual a oração modificadora acrescenta à oração núcleo nuanças variadas de sentido, que mostram afinidades semânticas dentro e entre domínios.

As ocorrências de (01) a (03), extraídas de amostras de fala, contribuíram para o levantamento de evidências de um processo de gramaticalização em curso, em que é possível flagrar grande flutuação de forma e de função. Nos três casos, a construção (a) hora que encabeça orações e poderia ser parafraseada por quando: eu só nasci, quando ele entrou; quando tirou o papel de parede, a gente viu que tava aquele mofo; quando tiver bem douradinho, a gente refoga o arro\%: Contudo, em (01), a construção preserva do item hora a acepção semântica mais básica de horário concreto em que se dá um evento, ao passo que, em (02) e (03), o significado de tempo cronológico é mais opaco, e as construções podem ser interpretadas também em termos de causa e de condição, respectivamente.

(01) (....... minha mãe falô(u) que eu não nascia... que eu só nasci a hora que ele entrô(u)... minha mãe fala que eu nasci... seis horas da manhã... (Iboruna/ AC:106)

(02) (...) aquela parte cheia de::... no reboque e a o(u)tra parte pintada que ele é azul... que antes tinha um papel de parede emba(i)xo daí a hora que tirô(u) o papel de parede a gente viu que tava aquele (cheio) aquele mofo (Iboruna/ AC:054)

(03) aí coloca a panela no fo:::go... põe um po(u)co de ó::leo... nós coloca a::lho... [Doc.: hum] cebo::la... [Doc.: uhum] hora que tivé(r) ... um po(u)co já bem do(u)radi::nho... a gente refoga o arroz::... né?... (Iboruna/AC:125) 
Em trabalhos anteriores, defendi que o heterogêneo conjunto dos elementos de junção é propenso à constante transformação no tempo, sendo ampliado por meio do reaproveitamento de elementos da língua, via processos de gramaticalização (Longhin-Thomazi, 2003, 2006, 2009, 2010). Meillet há tempos salientou a instabilidade inerente aos juntores e a procedência diversa de itens dessa classe: les origines des conjonctions sont d'une diversité infinie (...). Il n'y a pas d'espèce de mot qui ne puisse livrer des conjonctions (1948:169). Décadas antes, na grande obra de referência da escola neogramática, Hermann Paul (1886:389) afirmava que podemos apreender historicamente o nascimento das conjunções: as que servem para ligar orações desenvolvem-se em grande parte a partir dos advérbios conjuncionais ou de formas isoladas dos pronomes conjuncionais, que estão eventualmente ligadas a outras palavras. Ainda segundo ele, é importante até que ponto a origem da palavra se encontra obscurecida. Um tal obscurecimento é necessário, se há de considerar-se a palaura como simples elemento de ligação de oraçoes.

Mais recentemente, as pesquisas de Kortmann $(1997,2001)$ sobre gramaticalização de "subordinadores adverbais" nas línguas européias têm mostrado que as classes de palavras que mais frequentemente servem de ponto de partida para gramaticalização de juntores novos são advérbios, preposições, interrogativos, complementizadores e relativizadores. Em português, algumas categorias fonte parecem ser mais produtivas para a formação de juntores como, por exemplo, os advérbios pronominais (Longhin-Thomazi, 2006). Também a tendência à constituição de perífrases conjuncionais baseadas em $x+$ que é bastante fértil, sendo $x$ uma variável preenchida por palavras de classes diversas. Hagège (2001) e Heine e Kuteva (2007) fazem predições sobre a natureza morfossintática da variável e, a partir de evidências empíricas, sustentam a existência de três mais importantes canais de derivação: nominal, verbal e adverbial. Sobre o canal nominal, foco deste trabalho, os autores argumentam que nomes de sentido genérico - espacial, temporal ou modal tendem a dar lugar a conjunções, por meio de processos históricos tipicamente unidirecionais, como foi o caso de weil, do alemão, com a trajetória Tempo >Causa, e de while, do inglês, com a trajetória Tempo>Condição. Kortmann (1997) chama a atenção para a frequência com que núcleos nominais de orações relativas se desenvolvem em juntores temporais, que podem dar lugar a juntores causais, condicionais e contrastivos. Nesses termos, o fenômeno de mudança envolvendo (na) hora que, que investigo aqui, é uma instância representativa de uma estratégia de ampliação de conjunções comum a várias línguas. 


\section{Decisões metodológicas}

O primeiro desafio para estudo da construção foi metodológico: a questão do corpus. Inicialmente, para descrição e análise das construções foram estabelecidas duas amostras de textos da modalidade de enunciação escrita, representativas do português paulista dos séculos XVIII e XIX (Simões e Kewitz, 2006; Barbosa e Lopes, 2006), período amplamente reconhecido pela implementação de vários fenômenos de mudança, que conferiram ao português brasileiro contornos próprios. Uma das amostras reúne uma mescla de diferentes tradições de escrever cartas, para diferentes propósitos sociais; a outra, peças teatrais. O levantamento da construção nesse material acusou um número bem escasso de ocorrências que, de um lado, dificultou qualquer tentativa de aprofundamento de análise e sistematização, mas, de outro, forneceu alguns índices importantes para apreensão de etapas do processo histórico de derivação, principalmente acerca da descategorização morfossintática. A consulta em textos contemporâneos, representativos de tradições da oralidade, mostrou um número de ocorrências satisfatório, fator que determinou a escolha e o recorte do corpus. Portanto, as construções com hora são investigadas em inquéritos do banco de dados Iboruna, que abriga dados do português falado na região noroeste do estado de São Paulo. O banco foi coletado sob os critérios da sociolinguística variacionista, com o controle de variáveis de ordem extralinguística, e está dividido em amostras censo e amostras de interação. Para este trabalho, selecionei aleatoriamente quarenta inquéritos da amostra censo.

Quanto à metodologia, conjugo as abordagens quantitativa e qualitativa, subsidiadas pelo critério frequência, nos moldes de Bybee (2003). Segundo essa autora, nos estudos linguísticos, há dois métodos relevantes para apurar a frequência: a frequência token, que diz respeito à frequência textual de ocorrência de um item/construção independentemente de seu significado, e a frequência type, que diz respeito à frequência com que um padrão particular ocorre, podendo ser avaliada por meio da consideração das diferentes funções assumidas pelo item ou construção. Neste trabalho, a frequência token é obtida pela contagem geral das ocorrências de (na) hora que, e a frequência type, pela análise e quantificação dos diferentes padrões semântico-cognitivos da construção.

A propósito dessas decisões, a questão que se coloca é se é possível apreender, em perspectiva sincrônica, aspectos do processo de derivação em que o nome genérico hora em contiguidade com uma oração relativa é 
reanalisado como perífrase conjuncional. A investigação de fatos de gramaticalização, do ponto de vista sincrônico, resulta no reconhecimento de padrões fluidos e na possibilidade de ordená-los em um cline de crescente gramaticalidade, que sugere que os padrões mais abstratizados e (inter)subjetivizados sejam mais tardios (Hopper; Traugott, 1993; Traugott e König, 1991; Traugott, 1982). Respaldada nessa perspectiva, aproximo-me também de Kortmann (1997:176) para quem os sentidos sincronicamente relacionados também o são diacronicamente, uma vez que, a partir de sentidos derivados, verificados no viés sincrônico, podemos extrair pistas para reconstruir a direção das mudanças semânticas, no viés diacrônico.

\section{Fundamentos teóricos}

Analiso a construção (na) hora que no quadro teórico-metodológico da mudança gramatical, particularmente da mudança por gramaticalização, que é entendida aqui como processo gradual em que construções menos gramaticais, quando usadas em contextos específicos, se tornam mais gramaticais, em função de um conjunto de alterações (Hopper; Traugott, 1993; Heine, 2003; Heine e Kuteva, 2007). Tais alterações são abordadas por Heine (2003) e Heine e Kuteva (2007) em termos de quatro mecanismos: extensão contextual, dessemantização, descategorização e erosão. A singularidade da gramaticalização é garantida, segundo esses autores, pela interação entre esses mecanismos, que compõem uma ferramenta para identificação e descrição de casos de mudança.

Para descrever a extensão contextual, Heine e Kuteva (2007) propõem um roteiro de quatro estágios sucessivos, associados a diferentes tipos de contexto, conforme representado no Quadro 1. No estágio I, o item fonte (menos gramatical), sem restrições contextuais, veicula o significado original, mais concreto e, no estágio IV, veicula o significado gramatical, mais abstrato. Há entre I e IV dois outros estágios intermediários. No estágio II, gatilho da mudança, o item é usado em um novo contexto, que permite uma inferência. É o chamado contexto bridging, em que há dois (ou mais) significados, e um deles é contextualmente implicado. No estágio III, relacionado ao contexto switch, o significado alvo ganha o primeiro plano, tornando-se o único disponível, mas ainda requer a sustentação por traços contextuais. 
152 Sanderléia Roberta Longhin-Thomazi

\begin{tabular}{|l|l|l|l|}
\hline \multicolumn{1}{|c|}{ Estágio } & \multicolumn{1}{|c|}{ Contexto } & \multicolumn{1}{|c|}{$\begin{array}{c}\text { Significado } \\
\text { resultante }\end{array}$} & \multicolumn{1}{c|}{$\begin{array}{c}\text { Tipo de } \\
\text { inferência }\end{array}$} \\
\hline I inicial & Irrestrito & Significado fonte & - \\
\hline $\begin{array}{l}\text { II contexto } \\
\text { bridging }\end{array}$ & $\begin{array}{l}\text { Um novo contexto dispara } \\
\text { um novo significado }\end{array}$ & $\begin{array}{l}\text { Significado alvo } \\
\text { coexiste com } \\
\text { significado fonte: } \\
\text { ambiguidade }\end{array}$ & $\begin{array}{l}\text { Conversacional } \\
\text { (cancelável) }\end{array}$ \\
\hline $\begin{array}{l}\text { III contexto } \\
\text { switch }\end{array}$ & $\begin{array}{l}\text { Há um novo contexto que é } \\
\text { incompatível com o } \\
\text { significado fonte; }\end{array}$ & $\begin{array}{l}\text { Significado fonte fica } \\
\text { em segundo plano }\end{array}$ & $\begin{array}{l}\text { Convencional } \\
\text { (não-cancelável) }\end{array}$ \\
\hline $\begin{array}{l}\text { IV conven- } \\
\text { cionalização }\end{array}$ & $\begin{array}{l}\text { O significado alvo independe } \\
\text { de traços contextuais para } \\
\text { sustentá-lo; pode ser usado } \\
\text { em novos contextos. }\end{array}$ & Só o significado alvo & - \\
\hline
\end{tabular}

Quadro 1: Modelo de extensão contextual, segundo Heine e Kuteva (2007)

A dessemantização, estreitamente ligada à extensão, implica a perda e o ganho de traços de significado em função da pertinência ou não desses traços para o novo domínio. O princípio maior que rege essas alterações é a atitude mental, típica da espécie humana, em que conceitos do domínio físico são usados como veículos para expressão de conceitos do domínio mental, numa clara demonstração de que a passagem do lexical ao gramatical, ou do menos ao mais gramatical, se faz, da perspectiva semântica, por meio de um percurso que segue do concreto para o abstrato, ou seja, de um percurso que é metafórico em essência.

Em estudo tipológico sobre gramaticalização de subordinadores adverbiais, Kortmann (1997) propõe quatro grandes sistemas semânticocognitivos, dentro dos quais se desdobram conjuntos de relações com elos de parentesco, que ajudam a explicar padrões de polissemia: Tempo (simultaneidade, anterioridade, posterioridade, contingência, etc.), Modo (modo, comparação, meio, proporção, etc.), Lugar e CCCC (causa, condição, concessão, contraste). Segundo ele, do ponto de vista histórico, a mudança semântica é fortemente direcional. Os caminhos são condicionados pelas relações polissêmicas entre os sistemas semânticos, apontando para um aumento de complexidade, que pode ser capturado pela figura abaixo, que mostra afinidades maiores e menores entre as relações semânticas: (i) todas as relações podem dar lugar a CCCC, mas não vice-versa; (ii) lugar e modo virtualmente não têm afinidades semânticas e ambos alimentam os demais sistemas; (iii) o sistema temporal é o canal de derivação mais importante para as relações CCCC (indicado pela espessura da seta). 


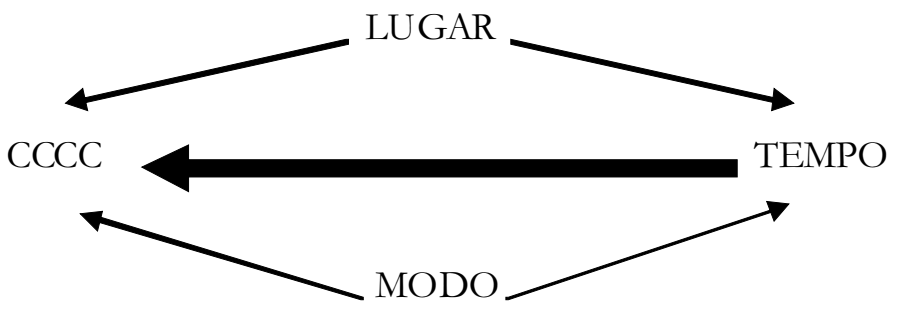

Esquema 1: Macroestrutura do universo semântico das relações oracionais (Kortmann, 1997)

Segundo Kortmann (1997), nas línguas européias, as trajetórias que tipicamente levam à emergência de subordinadores adverbiais causais e condicionais são:

CAUSA < Simultaneidade, Anterioridade, Término, Modo, Similaridade;

CONDIÇÃO < Contingência, Simultaneidade

No contexto dessas discussões, Kortmann (1997) propõe estender da filogênese para a ontogênese a investigação das tendências em mudança semântica envolvendo juntores, particularmente o desenvolvimento das relações de CCCC na linguagem infantil. Ele sustenta que, assim como na filogênese as direções na mudança semântica sinalizam uma complexidade cognitiva crescente, na ontogênese a ordem preferencial de aquisição dos esquemas de junção também segue um gradiente cognitivo similar.

O terceiro mecanismo, a descategorização, consiste na perda e ganho de traços morfológicos e sintáticos. Numa tentativa de generalização, Heine e Kuteva enumeram como propriedades mais salientes da descategorização a perda da propriedade de flexionar, da propriedade de receber modificadores, e da liberdade sintática. Já a erosão, segundo os autores, tem um papel menor. Embora não seja necessária para definir o processo de gramaticalização, apresenta-se como uma tendência regular em vários dos processos. Os tipos mais comuns de erosão são fonéticos, com perda de segmentos, sílabas, propriedades suprasegmentais, mas também em alguns casos são reconhecidas perdas morfológicas (Heine e Reh, 1984). 
154 Sanderléia Roberta Longhin-Thomazi

\section{Questões}

A análise de (na) hora que procura dar conta das seguintes questões:

(i) dada a transparência que caracteriza a construção - no sentido de que, em certos contextos, ainda é possível recuperar (parte d)o valor dos itens componentes - em que critérios podemos nos basear para defender que (na) hora que atua realmente como um juntor? A resposta será dada em 5.1, em que, à maneira de Kortmann (1997), lanço mão de três critérios que permitem avaliar o grau de prototipicidade de juntores perifrásticos.

(ii) qual o estatuto dos diferentes significados da construção tendo em vista as tendências em mudança semântica que acompanham a gramaticalização? Essa questão se desdobra em outras mais específicas: (a) quais significados são primários e quais são derivados?; (b) que critério(s) permite(m) distinguir os significados?; (c) em que medida o significado fonte e os padrões de polissemia evidenciam os caminhos da mudança semântica?; e, (d) em que medida os graus de complexidade cognitiva das relações de sentido se conformam às tendências em mudança semântica? As respostas serão dadas em 5.2 e 5.3, em que analiso as implicações semântico-pragmáticas da construção com hora.

(iii) em que medida a tradição textual em que o texto se insere contribui para compreensão dos fatos de uso e de mudança relacionados à (na) hora que? Segundo Kabatek (2006), o que caracteriza uma tradição textual/discursiva é uma combinação particular de elementos linguísticos, e os esquemas de junção, com suas possibilidades variáveis de realização quanto à arquitetura sintática e relações semântico-cognitivas, constituem um fenômeno privilegiado para apreensão das tradições. Ele sustenta que há uma correlação entre o tipo e a frequência dos juntores presentes no texto e a tradição na qual o texto se insere, e que os processos de inovação e adoção linguística no campo dos juntores encontram liberdade em certas tradições, mas não em outras. Para essa questão, a resposta será dada em 5.4, em que investigo quantitativamente a correlação entre os padrões da construção e frequência de uso nas tradições textuais que compõem o corpus. 
5. Análise dos dados

\subsection{Estatuto conjuncional de (na) bora que}

Atentando às propriedades morfológicas e semânticas dos juntores, Kortmann (1997) elenca uma série de critérios que permitem avaliar o caráter conjuncional mais e menos prototípico dos juntores e que, portanto, garantem um tratamento mais sistemático para essa classe que é heterogênea em essência. $\mathrm{O}$ autor enumera, entre outros, o fato de os juntores típicos não serem categorias flexionáveis, não cumprirem função sintática, e não terem ordem flexível na oração de que fazem parte. Com respeito aos juntores perifrásticos, em que nomes são seguidos por relativizadores ou por complementizadores, Kortmann afirma que precisam cumprir pelo menos um dos seguintes critérios:

(a) devem exibir uma fusão mínima;

(b) devem ter perdido pelo menos algumas de suas propriedades originais; e,

(c) devem ter pelo menos uma interpretação que não é totalmente recuperável a partir do significado das partes (condição de não-composicionalidade).

Aplicados às ocorrências de (na) hora que, a situação que se revela é que, quanto à (a), a fusão é relativa. Avalio a fusão em termos morfológicos como a invariabilidade na ordem dos elementos da construção e a impossibilidade de inserção de material interveniente. Embora a grande maioria das ocorrências se conforme a esses dois postulados, coexistem casos, como (04), em que que é pronome relativo introdutor de duas orações relativas, ambas articuladas a hora; e também casos, como (05), em que o advérbio lá se interpõe entre hora e que:

(04) eu tava dormindo... aí na hora que eu acordei, que eu vi eles gritando eu fui lá ver (Iboruna/AC:015)

(05) consegui batê( $(r)$ meu carro no carro deles ((inint)) pa vê(r) se o carro dele conseguia... se:: se nem capotasse na hora lá que nos tava (Iboruna/AC:107)

Para avaliação do critério (b), que diz respeito à perda de traços da forma fonte, recupero de (06) a (09) as quatro ocorrências encontradas nas 
amostras dos séculos XVIII e XIX, e as comparo com ocorrências do português atual, de (10) a (12):

(06) (...) o tempo de serviço é de 10 ás 3, mas durante todo esse tempo trabalho uma hora no maximo, emprego o resto em leituras e palestra; posso sahir á hora que necessitar, assim como receber qualquer pessoa que quizer fallar commigo (Correspondência passiva de Washington Luis: Carta 13)

(07) Raul (Saindo da direita e lendo o Globo.) — "À hora em que entrou a nossa folha para o prelo, ainda não se sabia...” [Caiu o Ministério, 1882]

(08) Henrique - Maldita seja a hora em que se lembraram de meter-me em semelhante comédia. [Como se fazia um deputado, 1882]

(09) Esse amor é impossível, Marianinha. Sem nome, sem família e sem fortuna, vejo-me repelido por teu pai e a consciência diz-me, nas horas em que a esperança vem acalentar-me, que devo fugir quanto antes desta casa. [Maldita parentela, 1887]

(10) Doc.:. éh::... eu queria agora que cê me falasse... éh:: uma idéia de como é o seu dia-a-dia... desde a hora que você acorda até... até o final do dia mesmo (Iboruna/AC:039)

(11) e EU:: eu tava VEN::do eu tava falan(d)o com a C. ... nessa hora... daÍ a hora que eu vi que a M. tava apanhan(d)o a gente foi LÁ::... (Iboruna/ AC:010)

(12) então a hora que o bacon tiver bem BEM torrado mesmo aí cê joga a car::ne... (Iboruna/AC:137)

A comparação entre os dois conjuntos de exemplos evidencia que houve perda de vários traços da construção original. Como as ocorrências mais antigas mostram, a fonte é uma construção relativa padrão - na hora em que - em que o nome antecedente hora, inserido em um sintagma preposicional, tem seu significado particularizado por uma oração relativa preposicionada. Os dados contemporâneos, por sua vez, mostram a forte tendência à erosão das preposições. Nas 118 ocorrências verificadas nos inquéritos do Iboruna, a preposição em é apagada em 100\% dos casos, favorecendo a contiguidade de hora e que; a preposição em do sintagma está em franco desaparecimento, com apagamento em $64 \%$ dos casos; e o artigo definido $a$, que também não tem relevância para a nova categoria, começa a ser perdido (14\% dos casos), conforme ilustram os dados da Tabela 01 abaixo. 


\begin{tabular}{|l|l|}
\hline na bora que & $43 / 118 \quad 36 \%$ \\
\hline a bora que & $58 / 118 \quad 50 \%$ \\
\hline hora que & $17 / 118 \quad 14 \%$ \\
\hline
\end{tabular}

Tabela 1: frequência das formas alternantes na hora que $\sim$ a hora que $\sim$ hora que nos dados de fala

As ocorrências permitem verificar também que o nome hora sofre descategorização e deixa de flexionar-se em número. A única ocorrência com pluralização é (09), extraída da amostra do século XIX. Além de propriedades gramaticais, o nome perde em concretude semântica e por isso passam a coexistir sentidos mais e menos concretos, conforme (10)-(12), que mostram que as relações temporais flutuam entre um tempo cronológico, do relógio, como em (10), que é uma construção mais transparente; e recortes de temporalidades criadas pelo falante, em construções mais opacas, como em (11) e (12), que também admitem, respectivamente, interpretação causal e condicional. Essas leituras causais e condicionais comprovam a possibilidade de interpretações independentes da significação das partes, atendendo, portanto, à exigência do critério (c) ${ }^{1}$.

O exame dos três critérios de Kortmann é relevante não só por atestar caráter conjuncional (ainda que flutuante) da construção, mas também por permitir vislumbrar o alcance de parâmetros da gramaticalização, tais como a descategorização, a semantização e a erosão morfológica (na hora em que $>$ na hora que $>a$ hora que $>$ hora que), que apontam para a convivência entre diferentes estágios de desenvolvimento da construção.

\subsection{Os padrões de (na) bora que}

Dos 118 token de (na) hora que distingui três type com base na informação semântico-cognitiva, o que indicia para a construção um considerável grau de não-discretude conceitual (polifuncionalidade semântica). Todos os padrões veiculam sentido de tempo, e o que os distingue é a possibilidade ou não de outras interpretações, de causa ou de condição. O estatuto dessas in-

1 Ocorrências que mostram a hesitação do falante na escolha dos juntores, tais como " $n a$ hora/ e quando o caminhão de gás vem encher o tanque" (AC:016), e "e se/ a hora que estivé(r) esfriando eu furo ele inte(i)ro..."(AC:067), podem ser interpretadas como índices da intuição do falante sobre o caráter juntivo de (na) hora que. 
terpretações será discutido logo adiante. A frequência dos padrões é apresentada na Tabela 2:

\begin{tabular}{|l|ll|}
\hline Tempo (T) & $43 / 118$ & $37 \%$ \\
\hline Tempo-causa (TCA) & $17 / 118$ & $14 \%$ \\
\hline $\begin{array}{l}\text { Tempo-condição (TCO) } \\
\text { Tabela 2: frequência type }\end{array}$ & $58 / 118$ & $49 \%$ \\
\hline
\end{tabular}

No padrão Temporal (T), reúno construções em que há uma sequencialidade de eventos no tempo, sem implicação de mudança de estado, conforme (13). No padrão Tempo-Causa (TCA) estão ocorrências em que a sequencialidade temporal resulta em uma implicatura de causa, i.é., o evento que vem primeiro é relevante para o evento que vem depois, em termos de causa/efeito, levando a uma mudança de estado, como em (14). No padrão Tempo-condição (TCO), estão as ocorrências em que a eventualidade resulta em uma implicatura de condição, como em (15).

\section{Tempo (T)}

(13) (...) aí a gente foi pro Vivendas... aí a gente ficô(u)... na HOra que ele chegô(u)... ele me chamô::(u)... de princesa (Iboruna/AC:27)

\section{Tempo-causa (TCA)}

(14) (...) ele tava indo de um lugar pro outro vindo sozinho... a hora que ele pôs a mão na porte(i)ra... a porte(i)ra abriu sozinha (Iboruna/AC:114)

\section{Tempo-condição (TCO)}

(15) (...) mistura ele no:: no fogo... hora que ele tiver $\mathrm{MO}:: \mathrm{RNO}$ aí você taca lá... seiscentas grama de leite condensado... (Iboruna/AC:89)

A interpretação dos padrões de (na) hora que pressupõe o reconhecimento de relações de parentesco semântico entre os domínios cognitivos de tempo, causa e condição. Acontece que, como comprovam os exemplos, nem sempre uma construção temporal vai permitir a derivação de uma causa ou de uma condição. Esse estado de coisas sugere não só polissemia entre os domínios, mas também polissemia interna ao domínio das relações de tempo, ou seja, sugere que na hora que codifica mais de um tipo de relação temporal e que, a depender dessa relação de tempo, temos trajetórias distintas de derivação. 
Por isso, investiguei o tipo de relação temporal subjacente a cada padrão. Para tanto, foi decisiva a consideração de características morfossintáticas como, por exemplo, o tempo verbal das orações envolvidas.

Os resultados estão na Tabela 3, em que, é possível observar, num primeiro momento, a frequência dos padrões quanto à ordenação das orações na construção. Considerando a totalidade de ocorrências, a construção (na) hora que é preferencialmente anteposta (99/118, ou 84\% dos casos) ${ }^{2}$, mas a distribuição não é a mesma pelos três padrões: a posposição tem frequência significativa só para o padrão Temporal (cf. exemplo (01).

\begin{tabular}{|l|l|c|c|c|c|c|}
\hline & & ANTER & SIMULT & POSTER & CONTING & TOTAL \\
\hline \multirow{2}{*}{$\mathrm{T}$} & Anteposta & $24 / 30(80 \%)$ & $4 / 30(13 \%)$ & $2 / 30(7 \%)$ & & $30 / 43(100 \%)$ \\
\cline { 2 - 7 } & Posposta & $8 / 13(61 \%)$ & $4 / 13(31 \%)$ & $1 / 13(8 \%)$ & - & $13 / 43(100 \%)$ \\
\hline \multirow{2}{*}{ TCA } & Anteposta & $15 / 15(100 \%)$ & - & - & - & $15 / 17(100 \%)$ \\
\cline { 2 - 7 } & Posposta & $2 / 2(100 \%)$ & - & - & - & $2 / 17(100 \%)$ \\
\hline \multirow{2}{*}{ TCO } & Anteposta & $1 / 54(2 \%)$ & $1 / 54(2 \%)$ & - & $52 / 54(96 \%)$ & $54 / 58(100 \%)$ \\
\cline { 2 - 7 } & Posposta & - & - & - & $4 / 4(100 \%)$ & $4 / 58(100 \%)$ \\
\hline
\end{tabular}

Tabela 3: Tipo de relação temporal codificada nas construções antepostas e pospostas

A Tabela 3 mostra que a construção (na) hora que pode codificar diferentes relações de tempo: anterioridade, simultaneidade, posterioridade e contingência. À maneira de Kortmann (1997), entendo que a contingência opera de maneira diferenciada no eixo do tempo, sinalizando uma habitualidade, uma eventualidade temporal, admitindo, em português, paráfrase com sempre que. 'Trata-se, portanto, de um tempo 'indefinido' se comparado às demais relações temporais. Os números e as hachuras na tabela salientam a forte correlação que parece existir, de um lado, entre Anterioridade e os dois primeiros padrões, que envolvem tempo e causa; e, de outro, entre Contingência e o padrão condicional. A acepção exclusivamente temporal de (na) hora que está respaldada na codificação de anterioridade, por meio de uma morfossintaxe que privilegia verbos nos pretérito perfeito e/ou imperfeito. A acepção de causa/efeito também está vinculada mais fortemente à anterioridade, e de-

2 Pereira e Paiva (2004) investigam, no quadro funcionalista da articulação de orações, o estatuto sintático das orações introduzidas por prep + det + nome temporal (hora, época e dia), que entendem como casos de gramaticalização. Em perspectiva sincrônica, analisam as construções à luz (i) da explicitude e identidade dos sujeitos; (ii) da relação proposicional entre as orações; e, (iii) da ordem das orações. Quanto à relação proposicional, também mostram a sobreposição de relações de sentido e, quanto à ordem, constatam a preferência pela anteposição. 
pende crucialmente da ordem icônica das orações em que a causa temporalmente precede o efeito. Por outro lado, quando há acepção de condição, a relação temporal é a de contingência, e predominam os verbos no presente e futuro.

A Tabela 4 abaixo, em que são apresentados os números absolutos da apuração do tempo verbal das orações núcleo e modificadora, reforça essas afirmações. A legenda prevê as opções P, I, F e E para, respectivamente, perfeito, imperfeito, futuro e presente. Nos pares que aparecem no eixo horizontal da tabela (PP, PI, IP, II, etc), a primeira letra indica o tempo da primeira oração da construção e a segunda, o tempo da segunda oração.

Legenda: $\mathrm{P}=$ Perfeito; $\mathrm{I}=$ Imperfeito $; \mathrm{F}=$ Futuro $; \mathrm{E}=$ Presente

\begin{tabular}{|l|c|c|c|c|c|c|c|c|c|c|c|}
\hline & PP & PI & IP & II & PF & EE & FF & FE & EF & PE & EP \\
\hline Tempo & $21 / 43$ & $13 / 43$ & $1 / 43$ & $2 / 43$ & - & $2 / 43$ & - & $1 / 43$ & $1 / 43$ & $1 / 43$ & $1 / 43$ \\
\hline $\begin{array}{l}\text { Tempo- } \\
\text { causa }\end{array}$ & $15 / 17$ & - & $1 / 17$ & $1 / 17$ & - & - & - & - & - & - & - \\
\hline $\begin{array}{l}\text { Tempo- } \\
\text { condição }\end{array}$ & - & $1 / 58$ & - & $2 / 58$ & $2 / 58$ & $29 / 58$ & $7 / 58$ & $14 / 58$ & $1 / 58$ & $1 / 58$ & $2 / 58$ \\
\hline
\end{tabular}

Tabela 4: Tempos verbais das orações núcleo e modificadora

Os números comprovam que as construções temporais e tempo-causais apresentam predominantemente verbos no perfeito: PP e PI; já as construções que permitem uma leitura condicional apresentam com mais frequência os verbos no presente e futuro: EF, FF e FE. São traços morfossintáticos importantes para sustentação dos sentidos.

\subsection{Polissemia e tendências em mudança semântica}

Dada a distinção entre os padrões, tempo, causa e condição são valores da construção (na) hora que ou são implicaturas pragmáticas, advindas de enriquecimentos interpretativos suscitados pelos traços contextuais? Admito que as relações de tempo são inerentes à construção (na) hora que, são recortes temporais que resultam da abstratização da noção de tempo cronológico do nome hora, e que as leituras de causa e de condição têm estatuto diferenciado: são conversacionais, ou seja, são sentidos derivados do sentido temporal, por meio de inferências baseadas na relevância e no fortalecimento da informatividade (Traugott e König, 1991). São, portanto, leituras fortemente dependentes do contexto. Como mostrado, a implicatura de causa é sugerida 
pela sequencialidade dos eventos no tempo, e a implicatura de condição, por uma relação de tempo habitual. E ambas coexistem com o sentido temporal, que não é anulado. À luz do modelo de contextos de Heine e Kuteva (2007), é possível afirmar que (na) hora que está associada a diferentes contextos bridging, que são altamente necessários para a mudança por gramaticalização. Os sentidos alvo poderão, ao longo do tempo, avançar para o estágio de convencionalização, quando estiverem livres das restrições contextuais que deram origem a eles e quando não for mais possível uma leitura em termos do significado fonte.

A análise de (na) hora que, conforme esboçada aqui, corrobora as pesquisas que mostram que a natureza temporal do item fonte ajuda a explicar os padrões de polissemia que são indicativos de graus de gramaticalidade, em perspectiva sincrônica (Causa e Condição são mais 'gramaticais' do que Tempo), assim como as trajetórias de mudança semântica observáveis em muitas línguas do mundo, em perspectiva diacrônica (Kortmann, 1997; Couper-Kuhlen; Kortmann, 2000). O esquema abaixo resume o trânsito de sentidos que vem ocorrendo na constituição de (na) hora que, confirmando expectativas que direcionam para um crescente de informação cognitiva.

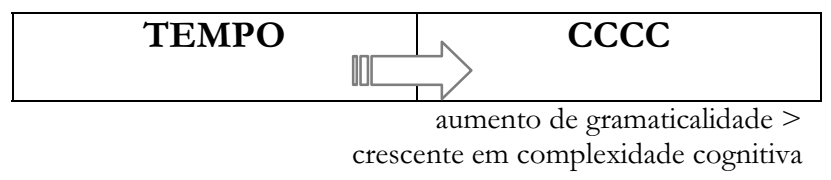

Esquema 2: Esboço geral do trânsito de sentidos de (na) hora que

Atentando ao estatuto cognitivo das implicaturas de causa e de condição, investiguei o comportamento de (na) hora que em termos da inserção da construção em diferentes domínios semântico-pragmáticos. Parti da diferenciação, evidenciada em Sweetser (1991), entre relações estabelecidas entre fatos do mundo real (domínio do conteúdo) e entre momentos de uma argumentação (domínio epistêmico). Com sugere a autora, a investigação do trânsito por esses domínios constitui um lugar privilegiado para observação de uma tendência filogenética que postula que os significados epistêmicos derivam daqueles de conteúdo e que, portanto, são historicamente mais tardios nas línguas. No âmbito do presente trabalho, a expectativa é a de que (na) hora que, por se tratar de uma construção em emergência, codifique primeira e predominantemente sentidos no domínio do mundo real. 
As relações de causa e de condição, tal como verificadas nas ocorrências, confirmam a tendência filogenética. Os resultados são categóricos: somente causais e condicionais no domínio do conteúdo sócio-físico. As relações causais, concretizadas no par causa/efeito, trazem uma representação cognitiva das experiências no mundo, como mostram os exemplos em (02), (11) e (14), mencionados anteriormente. Nas relações condicionais, o que se verifica é que o conteúdo de uma oração traz uma condição suficiente para a realização, no mundo real, do conteúdo que é expresso na outra oração, como mostram (03), (12) e (15). São condicionais habituais e genéricas construídas sobre referências temporais que permanecem até certo ponto explícitas ${ }^{3}$.

\subsection{O papel das tradições textuais}

A frequência dos padrões de (na) hora que se mostrou diferenciada em função das tradições textuais em que os textos se inserem. Para avaliar a possível relevância da tradição textual na opção pelo padrão da construção, codifiquei as ocorrências do corpus com base na seguinte classificação:

\begin{tabular}{|l|l|}
\hline Tipo textual & Tradição textual \\
\hline Narrativa & Conto $(\mathrm{C})$ \\
\hline Relato & Experiência pessoal $(\mathrm{E})$ \\
\hline Relato & Procedimento $(\mathrm{P})$ \\
\hline Relato & Opinião $(\mathrm{O})$ \\
\hline
\end{tabular}

O Gráfico 1 abaixo mostra que a expectativa de correlação entre os padrões de (na) hora que e a tradição textual se confirma, pois a depender da tradição há predisposição maior ou menor de certos padrões: contos e relatos de experiência pessoal favorecem os padrões temporais e causais, ao passo que os relatos de procedimento favorecem muito fortemente o padrão condicional. Relatos de opinião também se relacionam com o padrão condicional, mas em menor escala. Esses resultados ajudam a entender, pelo menos em parte, o insucesso da investigação em cartas e em peças teatrais dos séculos

\footnotetext{
A proximidade de funcionamento entre temporais e condicionais habituais é explorada por Moscow (2001), nos casos de ambiguidade envolvendo wenn, do alemão, e when, do inglês.
} 
XVIII e XIX. A tradição textual pode ser tomada aqui, à maneira do que propõe Traugott (2008), como um tipo de contexto "não-linguístico" de grande importância, a ser considerado na investigação das mudanças, aliado a outros fatores como contato e registro.

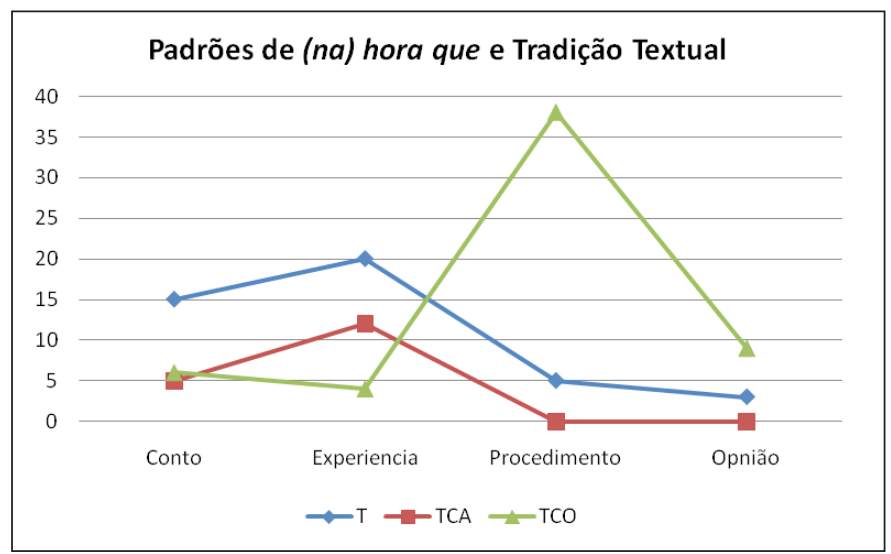

Gráfico 1: Frequência dos padrões de (na) hora que em função da tradição textual

No gráfico, as linhas referentes aos padrões temporal e tempo-causal são bastante similares, com pico maior em relatos de experiência. O que mais chama a atenção é o pico de frequência do padrão tempo-condição em relatos de procedimento. No corpus, os relatos de procedimento se referem, na maioria das vezes, às receitas culinárias. A frequência do tempo-condição nesse tipo de texto se justifica, conforme já salientado, pela especificidade noção temporal de habitualidade:

(16) Inf.: óh o café aqui a gente... coloca... á::gua... e já coloca o açúcar... [Doc.: uhum]] [então] cada COPO... d'água a gente coloca duas colher de açúcar... [Doc.: hum] então... a hora que FERve a água... com o açúcar... a gente coloca o pó... né?... calda bem o pó... e côa no coador de papel...(Iboruna/AC:125)

(17) Inf.: meu menino ama esse e tem um especial pra ele sabe?... você pega a goiabada você derrete um pedaço dela... com um po(u)co de água... na hora que ela fica bem cremosa dura... você pega esse creme branco e mistura com a... calda...(Iboruna/AC:106) 
164 Sanderléia Roberta Longhin-Thomazi

Conclusao

O tipo de relação temporal veiculado por (na) hora que ajuda a explicar as implicaturas de causa e de condição. O Quadro 2, inspirado em Kortmann (1997), sistematiza para a construção (na) hora que as relações de parentesco entre os dois grandes domínios - Tempo e CCCC - e mostra como o domínio de tempo alimenta o domínio de CCCC, particularmente as relações de causa e de condição, confirmando tendências na gramaticalização de juntores. Para a construção em estudo, os dados sugerem que, dentre as relações temporais instauradas, é a relação de Anterioridade que preferencialmente alimenta a implicatura de causa; e a relação de Contingência, a implicatura de condição. Ambos os sentidos de causa e de condição são conversacionais, dependentes ainda dos arranjos do contexto linguístico.

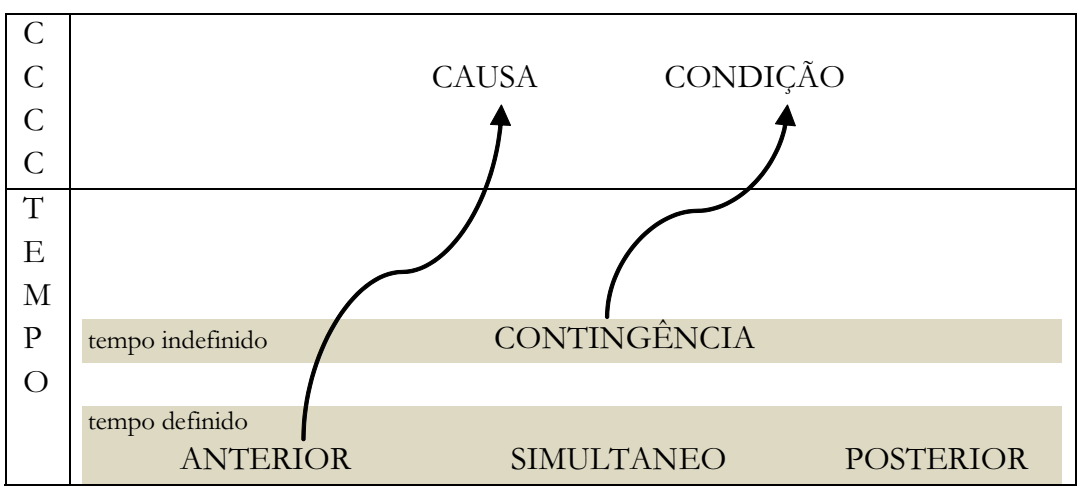

Quadro 2: Mapeamento cognitivo intra e inter-domínios das relações expressas por (na) bora que

As relações temporais são mais primitivas, mais básicas, e funcionam como ponto de partida para a emergência das relações causais e condicionais, que são, cognitivamente, mais complexas (Kortmann, 1997), corroborando, dessa forma, os recorrentes mapeamentos do tipo Tempo $>$ Causa e Tempo>Condição, que são canais preferidos de mudança semântica; e corroborando ainda a afirmação de Lühr (1989, apud Kortmann, 1997), de que Tempo é, sobretudo nas línguas européias, a categoria mais produtiva como fonte para vários significados conjuncionais. Tais fatos permitiram 'contar' um pouco da história de (na) hora que pelo viés sincrônico. 
Para resumir e finalizar, recupero de Kortmann (1997) a listagem de algumas tendências experimentadas por juntores adverbiais em gramaticalização, mostrando a aplicabilidade na explicação das alterações relacionadas à (na) hora que:

\begin{tabular}{|l|l|}
\hline \multicolumn{1}{|c|}{$\begin{array}{c}\text { Tendências na Gramaticalização } \\
\text { de juntores }\end{array}$} & \multicolumn{1}{|c|}{$\begin{array}{c}\text { Fatos da gramaticalização de (na) } \\
\text { bora que }\end{array}$} \\
\hline $\begin{array}{l}\text { 1. perda de transparência formal e } \\
\text { semântica }\end{array}$ & 1. formulaicidade: juntor perifrástico \\
\hline $\begin{array}{l}\text { 2. perda de substância } \\
\text { fonética/morfológica }\end{array}$ & 2. perda de preposição, perda do artigo \\
\hline 3. perda de liberdade sintática & 3. posição fixa no início da oração \\
\hline 4. desbotamento do conteúdo lexical & $\begin{array}{l}\text { 4. desbotamento do nome hora: } \\
\text { opacidade da noção de tempo } \\
\text { cronológico }\end{array}$ \\
\hline $\begin{array}{l}\text { 5. aumento de significados gramaticais, } \\
\text { com aumento da assimetria forma- } \\
\text { significado }\end{array}$ & $\begin{array}{l}\text { 5. desenvolvimento de significados } \\
\text { temporais, causal e condicional }\end{array}$ \\
\hline
\end{tabular}

\section{Referências bibliográficas}

BARBOSA, Afrânio; LOPES, Célia (orgs). 2006. Críticas, queixumes e bajulações na imprensa brasileira do século XIX: cartas de leitores. Rio de Janeiro:UFRJ/ FAPERJ.

BYBEE, Johan. 2003. Mechanisms of change in grammaticalization: the role of frequency. In: Joseph, B.; Janda, R. (eds.) The handbook of historical linguistics. Oxford: Blackwell.

COUPER-KUHLEN, Elizabeth; KORTMANN, Bernd. (eds). 2000. Cause, condition, concession, contrast: cognitive and discourse perspectives. Berlin, New York: Mouton de Gruyter.

HAGÈGE, Claude. Les processus de grammaticalisation. In: Haspelmath, M.; König, E.; Oesterreicher, W.; Raible, W. (eds). 2001. Language typology and language universals. Berlin, New York: Walter Gruyter.

HEINE, Bernd.; REH, Mechthild. 1984. Grammaticalization and reanalisys in African Languages. Hamburg: Helmut Buske.

HEINE, Bernd. Grammaticalization. In: Joseph, Brian; Janda, Richard (eds). 2003. The handbook of historical linguistics. Oxford: Blackwell Publishing.

HEINE, Bernd.; KUTEVA, Tania. 2007. The genesis of grammar: a reconstruction. Studies in the evolution of language. New York: Oxford University Press.

HOPPER, Paul; TRAUGOTT, Elizabeth. 1993. Grammaticalization. Cambridge: Cambridge University Press.

KABATEK, Johannes. Tradições discursivas e mudança linguística. In: Lobo, T; Ribeiro, I.; Carneiro, Z.; Almeida, N. (org) 2006. Para a história do português brasileiro. Salvador, EDUFBA. KORTMANN, Bernd. 1997. Adverbial subordination: a typology and history of adverbial subordinators based on European languages. Berlin, New York: Mounton de Gruyter. 


\section{Sanderléia Roberta Longhin-Thomazi}

Adverbial conjunctions. In: Haspelmath, M.; König, E.; Oesterreicher, W.; Raible, W. (eds) 2001. Language typology and language universals, Berlin, New York: De Gruyter.

MEILLET, Antoine. 1948. Linguistique bistorique et linguistique générale. Paris: Libraire Honoré Champion.

MOSCOW, Vera. Conditional constructions. In: Haspelmath, M.; König, E.; Oesterreicher, W.; Raible, W. (eds). 2001. Language typology and language universals. Berlin, New York: Walter Gruyter, vol. 1.

PAIVA, Maria Conceição; PEREIRA, Marli. 2004. Estatuto sintático das orações introduzidas pelas construções (prep) $+\operatorname{det}+\mathrm{N}$ temporal $+($ prep) + que. Juiz de Fora, Veredas, v.8, n. 1 e 2, p.245-258.

PAUL, Hermann. 1886. Prinzipien der sprachgeschichte. Tradução portuguesa de Maria Luiza Schemann: Princípios Fundamentais da História da Lingua. Lisboa: Fundação Calouste Gulbenkian. SIMOES, José; KEWITZ, Verena (org). 2006. Cartas paulistas dos séculos XVIII e XIX: uma contribuição para os corpora do PHPB. São Paulo: Humanitas/FFLCH/USP.

SWEETSER, Eve. 1991. From etymology to pragmatics. Cambridge: Cambridge University Press.

TRAUGOTT, Elizabeth. From propositional to textual and expressive meanings: some semantic-pragmatic aspects of grammaticalization. In: Lehmann, W., Malkiel, Y. (eds), 1982. Perspectives on historical linguistics. Amsterdam, John Benjamins, pp.245-271.

The status of onset contexts in analysis of micro-changes. In: Merja Kyto (ed). 2008. English corpus linguistics: crossing paths. Amsterdam/New York: Rodopi.

TRAUGOTT, Elizabeth, KÖNIG, Ekkehard. "The semantic-pragmatics of grammaticalization revisited”. TRAUGOTT, E., HEINE, B. (orgs.). 1991. Approaches to grammaticalization. John Benjamins Publishing Company.

Recebido em: 05/dez./2010

Aprovado em: 05/mai./2011 